\title{
DEEP INFECTION AFTER TOTAL HIP REPLACEMENT
}

\author{
H. J. ANDREWS, G. P. ARDEN, G. M. HART, J. W. OWEN
}

From Heatherwood Hospital, Ascot, and Wexham Park'Hospital, Slough

\begin{abstract}
Sixty-eight patients suffering deep infection from a consecutive series of 1746 total hip replacement operations are reviewed. The infection rate has been reduced considerably by improved technique and multiple antibiotic prophylaxis without the use of a special operation enclosure. Factors affecting deep infection are analysed and discussed.
\end{abstract}

Deep infection after total hip replacement may be defined as the presence of a persistent discharge which appears on clinical or radiological examination to arise from around the prosthesis (Figs 1 and 2). Using this definition we report on 68 patients suffering deep infection from a series of 1746 total hip replacements carried out between 1966 and 1978. We have considered the factors which are known to influence infection, and as a result have evolved a prophylactic antibiotic regime while also improving our operative technique. We use standard operating conditions without a special sterile enclosure.

From 1966 to 1969, 262 patients were given prophylactic penicillin $\mathrm{V}$ for two weeks after operation. These patients had an infection rate of 10 per cent. A second group of 461 patients, operated on between 1970 and 1972, had no antibiotics after operation and had an infection rate of 6.3 per cent. Between 1973 and 1978,1023 patients were given multiple antibiotics before, during and after operation and the infection rate was 1.3 per cent (Fig. 3). This rate is comparable with those reported from units using special theatre enclosures.

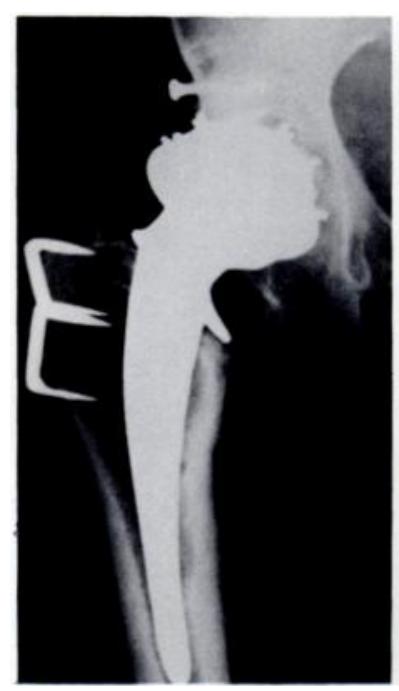

Fig. 1

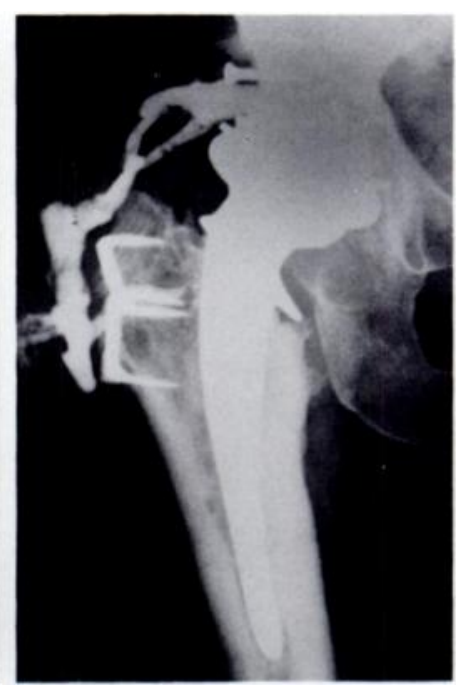

Fig. 2

Figure 1-Radiograph of the right hip of a patient aged 55 one year after a McKee arthroplasty with a good initial result. She developed pain and discharge from the wound. The radiograph shows cavitation around the stem of the prosthesis with sclerotic changes in the femoral shaft. Figure 2-Sinogram of the same patient showing a sinus extending down to the prosthesis. A staple at the bottom of the sinus was removed but healing did not occur until the prosthesis and all the cement were removed.

\section{TECHNIQUE 1973-1978}

The treatment regime used from 1973 to 1978 starts before operation, with careful enquiry and search for any sepsis elsewhere in the patient. If found, this is treated and the operation postponed. Patients on long-term drugs which may interfere with normal collagen formation or the normal production and function of lymphocytes, such as corticosteroids, penicillamine and cytotoxic drugs, have these drugs stopped or reduced to the lowest possible level for some months before operation. Drugs such as aspirin may give rise to secondary anaemia. Roles in 1971 reported that patients with a haemoglobin level of less than 10 grams per 100 millilitres are more liable to develop an infection.

Antibiotic cover starts with systemic cloxacillin; one gram is given intramuscularly with premedication and continued six-hourly for one

week. During operation the wound is washed out several times with physiological saline containing neomycin 1 per cent and polymyxin 150000 units per litre. Fusidic acid 0.5 gram is incorporated in the CMW or Simplex cement used, both for the acetabulum and for the femur. Two grams of chloramphenicol powder is sprinkled into the wound before closure.

Several large tension sutures are used to reduce dead space and the wound is drained for four to five days with three Redivac drains to reduce the incidence of haematoma. Blood is given before operation if necessary, to maintain the patient's haemoglobin level at or above 11 grams per 100 millilitres. A further two to three units are transfused during and after operation. Routine cultures are made from the ends of drains when they are removed.

H. J. Andrews, MRCP, FRCPath, King Edward VII Hospital, Windsor, Berkshire, England.

G. P. Arden, FRCS, 1 Dorset Road, Windsor, Berkshire SL4 3BA, England.

G. M. Hart, FRCS, 3 The Gables, Vale of Health, London NW3, England.

J. W. Owen, FRCS, Queen Elizabeth Hospital, Adelaide, Australia.

Requests for reprints should be sent to Mr G. P. Arden.

(C) 1981 British Editorial Society of Bone and Joint Surgery 0301-620X/81/00190053\$2.00 
H. J. ANDREWS, G. P. ARDEN, G. M. HART, J. W. OWEN

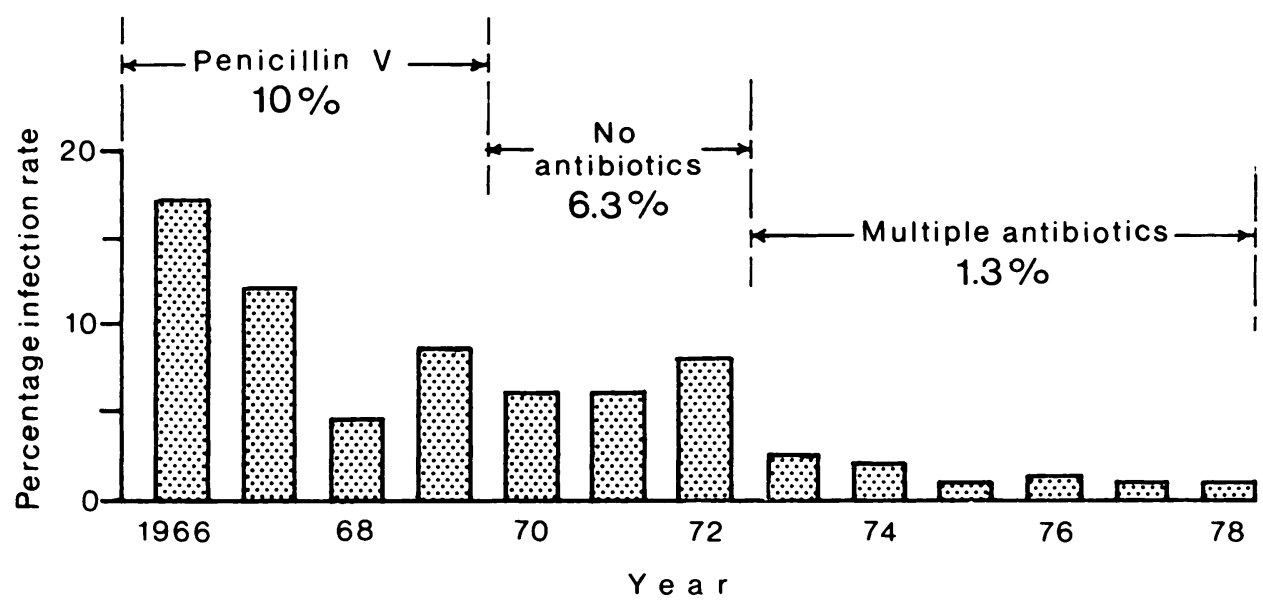

Fig. 3

Histogram relating annual percentage infection rate to prophylactic regime over a 12 -year period.

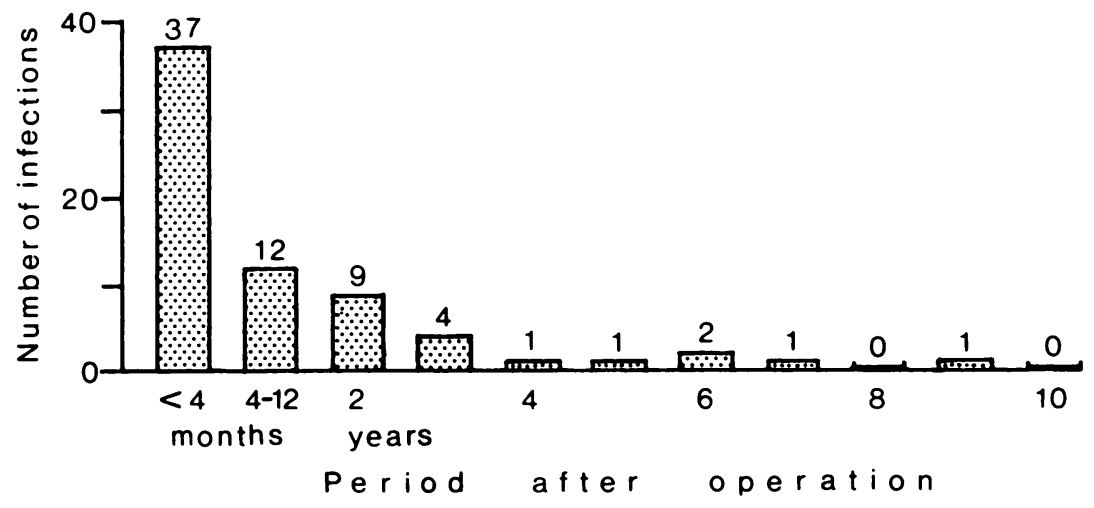

Fig. 4

Histogram showing the interval between operation and onset of infection in the 68 hips.

Table I. Result in 64 infected hips

\begin{tabular}{|lr|}
\hline $\begin{array}{l}\text { Prosthesis and cement removed } \\
\text { and wound healed }\end{array}$ & 39 \\
$\begin{array}{l}\text { Prosthesis and cement removed } \\
\text { and wound failed to heal }\end{array}$ & 8 \\
Sinus present & 6 \\
Healed with rest & 6 \\
Healed with drainage & 2 \\
Revised & 2 \\
Not known & 1 \\
& $\frac{64}{}$ \\
\hline
\end{tabular}

\section{RESULTS}

We have studied 68 hips in 65 patients with deep infection. Four patients died of unrelated causes, and 64 hips were followed to a result. The majority of the patients with persistent deep infections required removal of prosthesis and cement before healing occurred (Table I). Fifty-three patients were female, 12 were male; three had bilateral infection. Most of the
Table II. Infection rate according to diagnosis

\begin{tabular}{|l|r|c|c|}
\hline \multirow{2}{*}{\multicolumn{1}{|c|}{ Diagnosis }} & \multirow{2}{*}{ Operations } & \multicolumn{2}{c|}{ Infected hips } \\
\cline { 3 - 4 } & 1258 & Number & Percentage \\
\hline Osteoarthritis & 276 & 29 & 1.8 \\
Rheumatoid arthritis & 181 & 13 & 10.5 \\
Still's disease & 26 & 2 & 7.2 \\
Ankylosing spondylitis & 5 & 1 & 20.7 \\
Trauma & 1746 & 68 & 3.9 \\
\hline Total & & &
\end{tabular}

replacements were performed for osteoarthritis but there was an unusually high proportion (28 per cent) who were suffering from adult or juvenile rheumatoid disease or from ankylosing spondylitis (Table II). Follow-up has been from one to 12 years with a mean of three years.

Staphylococcus aureus was the most common cause of early infection; other organisms were more common 
Table III. Occurrence of early (within three months) and late sepsis in 68 infected hips, related to the isolation of Staphylococcus aureus

\begin{tabular}{|l|c|c|c|c|c|c|}
\hline \multirow{2}{*}{} & \multicolumn{5}{|c|}{ Prophylactic regime } \\
\cline { 2 - 7 } & \multicolumn{2}{|c|}{$\begin{array}{c}\text { Penicillin V } \\
1965-1969 \\
n=262\end{array}$} & \multicolumn{2}{c|}{$\begin{array}{c}\text { Nil } \\
1970-1972 \\
n=461\end{array}$} & $\begin{array}{c}\text { Multiple antibiotics } \\
1973-1978 \\
n=1023\end{array}$ \\
\cline { 2 - 7 } & Number & Percentage & Number & Percentage & Number & Percentage \\
\hline Staphylococcus aureus & 4 & 1.5 & 7 & 1.5 & 5 & 0.5 \\
Other & 3 & 1.1 & 4 & 0.9 & 0 & - \\
Staphylococcus aureus & 8 & 3.0 & 4 & 0.9 & 2 & 0.2 \\
Other & 5 & 1.9 & 9 & 2.0 & 4 & 0.4 \\
No growth & 6 & 2.3 & 5 & 1.1 & 2 & 0.2 \\
\hline Total infected hips & 26 & 10.0 & 29 & 6.3 & 13 & 1.3 \\
\hline
\end{tabular}

in late infections (Table III). Bacteriological findings are set out in Table IV.

The majority of infections (54 per cent) occurred within four months of operation and a further 18 per cent occurred within one year. The remaining patients suffered late infections up to 10 years after operation (Fig. 4). Two of these followed septicaemia.

Table IV. Organisms isolated from 68 hips, 34 of which had multiple infecting organisms

$\left.\begin{array}{|l|r|}\hline & \text { Number of isolates } \\ \hline \text { Gram-positive } & 32 \\ \text { Staphylococcus aureus } & 15 \\ \text { Staphylococcus albus } & 14 \\ \text { Streptococci } & 7 \\ \text { (Enterococci } & \\ \text { Lancefield groups A, C, G 7 } & \\ \text { Aerobic spore-bearer } & 1\end{array}\right\} 62$

The infection in the osteoarthritic patients was divided evenly between early and late types, but in rheumatic diseases the highest incidence was immediately or soon after operation (Table V).

\section{FACTORS INFLUENCING SEPSIS}

Diagnosis. Apart from one infection from the five patients operated on after trauma to the hip, the infection rate in patients with rheumatoid arthritis was the highest, being five times greater than in those suffering from degenerative disease. The rheumatoid group, although younger, were generally less fit and this may have contributed to this result. Charnley (1972) reported a ratio of 1.76 to 1 of infection in rheumatoid as compared with osteoarthritic patients.

Previous operations. The incidence of deep infection was doubled in those patients who had undergone a previous operation such as osteotomy or nailing of a fracture. Dupont and Charnley (1972) also reported a twofold increase.

Type of prosthesis. The infection rate was highest with the metal-on-metal McKee-Farrar prosthesis, but this was being used during a period when sepsis was frequent. The McKee-Arden metal-on-plastic prosthesis was used for the majority of patients from 1972 to

Table V. Percentage infection rate related to time after operation

\begin{tabular}{|l|c|c|}
\hline Time after operation & Osteoarthritis & Rheumatic diseases \\
\hline Immediate & 0.3 & 3.5 \\
1 to 3 months & 0.6 & 2.0 \\
4 to 12 months & 0.4 & 1.4 \\
Over 1 year & 0.5 & 1.8 \\
\hline
\end{tabular}


1978. It would appear in this series that the type of prosthesis used has no significance in relation to infection.

Complications after operation. A dislocation after operation was particularly liable to lead to infection, and had occurred in 16 per cent of the infected patients, whereas the dislocation rate for the whole series was three per cent. Deep haematoma, occurring in seven of our patients, may also predispose to sepsis.

Drugs. Most of the rheumatoid patients were on routine medication, usually aspirin compounds or antiinflammatory drugs such as phenylbutazone or indomethacin. These drugs did not appear to affect the incidence of infection. Corticosteroids given for prolonged periods result in thin skin and fragile vessels. We have previously reported no significant difference in healing between one group given cortisone and another given codeine as a placebo (Arden 1956). More recently a similar trial was carried out with penicillamine and again showed no significant difference from controls (Ansell, Moran and Arden 1976).

Anticoagulants. Most patients were not given prophylactic anticoagulants. A small series were on low doses of heparin, but showed an increased incidence of wound haematoma and its use was abandoned. More recently one gram of aspirin daily for two weeks has been given as an antithrombotic agent. This has not affected the incidence of wound infection.

Other infections. Superficial infection of the wound produces an increased risk of later deep infection, but Charnley (1972) reported that most cases of deep infection followed primary healing. Sepsis elsewhere in the body may be a potent cause of a deep infection, and 12 of the patients in this series had such a lesion. All but one of these were suffering from rheumatoid arthritis or Still's disease. Urinary infection was present in six, pressure sores in three, bronchitis in two, while one was suffering from cholecystitis.

\section{DISCUSSION}

Charnley and Eftekhar (1969) reported 17 cases of infection after 190 total hip replacements in their first series. The infection rate was 8.9 per cent and fell to 1.3 per cent with better operating techniques and the use of a sterile air enclosure. An increasing number of reports on infection after total hip replacement have been published with infection rates varying from 11 per cent (Wilson et al. 1972) to none (Collis and Steinhaus 1976). The number of operations reported and the length of follow-up has varied widely. Factors which have reduced infection rates have included operating techniques and conditions. The use of prophylactic antibiotics, the indications for the operation, and the length of follow-up have also affected the reported results. Most of these series show staphylococcal infection in about 60 per cent, with Gram-negative organisms isolated in about 20 per cent. Sterile cultures have been reported to vary from 2 to 12 per cent.

Staphylococcus aureus has been the major cause of deep sepsis in this as in other series, occurring in nearly half of the 68 infected hips. No significant change in early infection with Staphylococcus aureus occurred when penicillin $\mathrm{V}$ prophylaxis was discontinued (Table III). The use of cloxacillin and the incorporation of fusidic acid into the cement reduced the incidence of early staphylococcal infections from 1.5 per cent to 0.5 per cent. No other organism appeared as a primary pathogen within three months of operation in 1023 consecutive operations although fusidic acid has no effect on Gram-negative bacilli. This could be attributed to the antibiotic washout or to the chloramphenicol powder placed in the wound before closure, or to both. Benson and Hughes (1975) found no significant difference in results with or without chloramphenicol.

Late infection may occur up to 10 years or even later after operation and show itself by pain in the hip or by abscess formation. The erythrocyte sedimentation rate is usually raised and radiographs may show cavitation around the prosthesis. These infections may settle with rest and a course of antibiotics, and the patient may regain good function in the hip. A few patients will have a chronic sinus and yet have a good hip function; these are given a prolonged course of antibiotics but are not treated surgically.

Staphylococcus aureus infections developing after more than three months decreased during the period with no antibiotic prophylaxis (Table III). Late sepsis associated with other organisms remained at the same level as in the penicillin $V$ period but fell from 2.0 to 0.4 per cent with the use of multiple antibiotic prophylaxis. It seems unlikely that local chloramphenicol or the neomycin and polymyxin irrigation could cause any marked antibacterial effect after three months. Synergistic mixed infections may be important and reduction of staphylococcal sepsis could have an indirect effect by reducing the ability of other organisms to cause sepsis. When an infected prosthesis is removed a staphylococcus may be isolated from deep in the wound though it could not be cultured from the original sinus. McKee (1970) has suggested that a late sterile discharge may arise from loosening of the prosthesis, but this has not been our experience.

Abolition of sepsis after operation is the aim of prophylaxis. Ericson, Lidgren and Lindberg (1973) reported no sepsis in patients who were given cloxacillin for two weeks; and Fitzgerald et al. (1973) had only two cases of Staphylococcus aureus infection in 658 cases. In the present series in the 1023 patients who were given multiple prophylactic antibiotics, seven hips became infected with Staphylococcus aureus, five of them within three months of operation. Resistance to the antibiotics used was not a factor in infection as all the organisms isolated were sensitive on disc testing to both cloxacillin 
and fusidic acid. However Pollard et al. (1979 a, b) found that levels of flucloxacillin in bone and synovial fluid after intramuscular injection given one hour before operation were not high enough to inhibit all strains of Staphylococcus aureus. The intravenous route was used by Fitzgerald et al. (1973) who gave methicillin while the cement was polymerising. The delayed absorption of drugs from intramuscular sites in the unconscious patient is known and may be the reason for infection despite the antibiotics given in the present series.

Deep infection after a total hip replacement is a serious complication and usually requires the removal of the prosthesis before healing will occur. The incidence of this complication has been gradually reduced in our series to about 1.3 per cent. This has been achieved by improved theatre technique, without the use of a special enclosure and, since 1973 , by the use of prophylactic antibiotics. The relative cost-effectiveness of the latter two methods is uncertain.

Some infections may not appear until many years after operation; these are usually metastatic and originate from infection in the lungs, urinary tract, teeth, or elsewhere (Downes 1977). The use of prophylactic antibiotics when these infections occur may protect the hip arthroplasty, and a card advising this is given to all our patients who have had total joint replacement.

\section{REFERENCES}

Ansell BM, Moran H. Arden GP. Penicillamine and wound healing in rheumatoid arthritis. Proc $R$ Soc Med 1976;70 Suppl 3:75-7.

Arden GP. Comparison of cortisone acetate and a codeine mixture as adjuvant treatment in Judet arthroplasty. Ann Rheum Dis 1956;15:173-5.

Benson MKD, Hughes SPF. Infection following total hip replacement in a general hospital without special orthopaedic facilities. Acta Orthop Scand 1975;46:968-78.

Charnley J, Eftekhar N. Postoperative infection in total prosthetic replacement arthroplasty of the hip-joint. Br J Surg 1969;56:641-9.

Charnley J. Postoperative infection after total hip replacement with special reference to air contamination in the operating room. Clin Orthop 1972;87:167-87.

Collis DK, Steinhaus K. Total hip replacement without deep infection in a standard operating room.J Bone Joint Surg [Am] 1976;58-A:446-50.

Downes EM. Late infection after total hip replacement. J Bone Joint Surg [Br] 1977;59-B:42-4.

Dupont JA, Charnley J. Low-friction arthroplasty of the hip for the failures of previous operations. J Bone Joint Surg [Br] 1972;54-B:77-87.

Ericson C, Lidgren L, Lindberg L. Cloxacillin in the prophylaxis of postoperative infections of the hip. J Bone Joint Surg [Am] 1973;55-A:808-13, 843.

Fitzgerald RH Jr, Peterson LFA, Washington JA II, Van Scoy RE, Coventry MB. Bacterial colonization of wounds and sepsis in total hip arthroplasty. J Bone Joint Surg [Am] 1973;55-A:1242-50.

McKee GK. Indications for total prosthetic replacement of the hip. J Bone Joint Surg [Br] 1970;52-B:772.

Pollard JP, Hughes SPF, Scott JE, Evans MJ, Benson MKD. Antibiotic prophylaxis in total hip replacement. Br Med J 1979a;1:707-9.

Pollard JP, Hughes SPF, Evans MJ, Scott JE, Benson MKD. Concentration of flucloxacillin in femoral head and joint capsule in total hip replacement. $J$ Antimicrob Chemother 1979b,5:721-6.

Roles NC. Complications of total prosthetic replacement of the hip and knee joints. J Bone Joint Surg [Br] 1971;53-B:760.

Wilson PD, Amstutz HC, Czerniecki A, Salvati EA, Mendes DG. Total hip replacement with fixation by acrylic cement.J Bone Joint Surg [Am] 1972;54-A:207-36. 